\title{
PRODUCCIÓN DE CRISANTEMO EN MACETA PARA FLORACIÓN EN DICIEMBRE CON USO DE DIFERENTES SUSTRATOS
}

\section{CHRYSANTHEMUM POT PRODUCTION FOR FLOWERING IN DECEMBER, WITH USE OF DIFFERENT SUBSTRATES}

\author{
Ahumada, V., Espinoza, C., Schiappacasse, F. y Carrasco, G. \\ Facultad de Ciencias Agrarias, Universidad de Talca, \\ Casilla 747, Talca, Chile \\ E-mail: fschiap@utalca.cl
}

\section{INTRODUCCIÓN}

El crisantemo (Dendranthema grandiflora) en maceta es un producto altamente demandado a nivel nacional. En la VII región ha sido tradicionalmente cultivado para floración natural en otoño. Siendo una planta de día corto, es posible programar su floración en otras épocas del año, y la navidad es una época en que aumenta la demanda. Por otra parte, los productores enfrentan el problema de abastecimiento de un sustrato para el llenado de sus macetas que sea uniforme de año en año, sin problemas sanitarios (ej. nemátodos), abundante y de bajo precio. La tierra de hojas ha sido hasta ahora la mejor alternativa, sin embargo no es uniforme de año en año y no es ambientalmente sustentable, ya que se extrae de los bosques de la zona central. En la región el aserrín de pino es muy abundante, y la corteza de pino, proveniente de la VIII región es ampliamente utilizada en horticultura. En cambio, el aserrín normalmente no es utilizado fresco, y esto se debería a su alta relación C/N (Nelson, 1991, Starbuck, 1994) y su posible toxicidad (Nelson, 1991), pero sí se ha utilizado exitosamente mezclado con el suelo (Cotter, 1974).

\section{MATERIALES Y MÉTODOS}

La investigación se llevó a cabo en la localidad de Vilches, latitud $35^{\circ} 29^{\prime}$ (S) y longitud $70^{\circ} 58^{\circ}$ (W), comuna de San Clemente, VII Región, Chile. A comienzos de agosto se tomaron estacas desde plantas madre del cultivar Marina (tipo belga), mantenidas bajo invernadero de polietileno. El cultivar florece al cabo de 8 semanas de iniciados los días cortos, según catálogo. Las estacas se enraizaron en cama caliente con perlita y bajo nebulización una a dos veces al día, y con días largos mediante luces de halógeno que iluminaban durante 3 horas en la mitad de la noche. El 23 de agosto se trasplantaron a macetas de $17,5 \mathrm{~cm}$ de diámetro superior (13,2 cm el inferior) y $14 \mathrm{~cm}$ de altura llenas con los siguientes sustratos: aserrín fresco de pino, aserrín y corteza de pino en proporciones 1:1, 2:1 y 3:1. Las plantas fueron despuntadas el 11 de septiembre y se mantuvieron siempre bajo días largos hasta su traslado al exterior, que ocurrió el 6 de noviembre. Desde ese momento se aplicaron días cortos mediante un polietileno grueso negro, que se extendió sobre las plantas desde las $7 \mathrm{pm}$ hasta las 9 am del día siguiente. El fertilizante utilizado fue Ultrasol de crecimiento; bajo días largos se aplicó semanalmente en concentración de 82,5 ppm de $\mathrm{N}$. Bajo días cortos se hicieron dos tratamientos con solución de Ultrasol de desarrollo de 200 ppm de N; en uno se aplicó la solución diariamente y en el otro cada tercer día. Bajo días largos se aplicaron $250 \mathrm{ml}$ de solución a cada maceta, y bajo días cortos se regó con manguera a saturación.

El diseño experimental fue de parcelas divididas, con dos factores. El factor principal fue el tipo de sustrato, con 4 niveles, y el segundo factor fue la frecuencia de aplicación de la solución, con dos niveles. Se utilizaron 15 plantas por repetición, 
y 3 repeticiones por tratamiento, dando un total de 360 plantas al ser 8 tratamientos.

Se realizaron evaluaciones de diámetro y altura de plantas (sobre 10 individuos), color del follaje, días a botón floral visible, días a botón coloreado y días a floración. Además se midió el $\mathrm{pH}$ de los diferentes sustratos a contar de la primera semana desde el inicio de los días cortos. Se realizará un análisis de varianza, y cuando corresponda se aplicará el test HSD.

\section{RESULTADOS}

Las plantas han mostrado un buen desarrollo en todos los sustratos utilizados. Se presentan los resultados obtenidos hasta la fecha.

\section{REFERENCIAS}

COTTER, D.J. 1974. Yield of successive cropping of tomato in sawdust and bark media. HortScience 9(4):387-388.

NELSON, P.V. 1991. Greenhouse operation and management. USA, New Jersey, Prentice Hall, p. 185.

STARBUCK, C. 1994. Applying Research in Forestry. Report $\mathrm{N}^{\circ} 6$. Using sawdust as a soil amendment. Disponible en: http://mdc.mo.gov/ documents/forest/managers/19941106.pdf

Agro Sur 35 (2): 32-34 2007

\title{
ALMACENAMIENTO DE POSCOSECHA Y VIDA EN FLORERO DE FOLLAJE JUVENIL DE Eucalyptus gunnii Hook. F. (Myrtaceae) PARA USO EN FLORISTERÍA
}

\section{POST HARVEST STORAGE AND VASE LIFE OF JUVENILE FOLIAGE OF Eucalyptus gunni Hook. F. (Myrtaceae) FOR FLORIST USE.}

\author{
Rebolledo, C.; Figueroa, I.; Wilckens, R. y Finot, L. \\ Facultad de Agronomía, Universidad de Concepción, \\ Casilla 595, Chillán, Chile \\ E-mail: ifigueroa@udec.cl
}

\section{INTRODUCCIÓN}

Eucalyptus gunni es una de las especies de follaje de corte más populares (Jones y Sedgley, 1993), sin embargo, al igual que las flores su calidad diminuye después de la cosecha debido a factores como presencia de etileno, disminución de la absorción de agua y de carbohidratos. También se han observado cambios morfológicos en la estructura de los tejidos vasculares en cortes transversales de la base de tallos de rosa, lo que podría afectar la absorción y transporte de agua a lo largo del tallo acelerando su marchitez (Carpenter y Rasmussen, 1973). Dentro de los parámetros de calidad del follaje de eucalipto, el color verde grisáceo de las hojas es su principal atractivo, lo cual se debe a la presencia de ceras epicuticulares presentes, principalmente, en la lámina foliar, las cuales regulan la relación de agua dentro de la planta y se van degradando a medida que los tallos senescen (Hallam y Chambers, 1970, Jones y Sedgley, 1993). Por lo anterior, el objetivo de la investigación es evaluar diferentes soluciones preservantes y períodos de almacenamiento de tallos juveniles de Eucalyptus gunnii destinados a floristería para prolongar la vida postcosecha. 